\title{
Proceeding
}

11th World Congress of Performance Analysis of Sport, 16-18 November 2016. International Society of Performance Analysis of Sport. Alicante, Spain

\section{Analysis of swimming technique among elite finswimmers}

\author{
VLADIMIR KUNITSON \\ School of Natural Sciences and Helth, Tallinn University, Estonia
}

\begin{abstract}
Finswimming is a sport where the athlete uses one big monofin to produce the propulsion. The purpose of this study was to describe the parameters of the swimming technique among elite class finswimmers. Methods: 18 elite level monofin swimmers, 10 male (age $25.3 \pm 5,2$ height 182,3 $\pm 10.9 \mathrm{~cm}$., weight $88.1 \pm 4.6$ $\mathrm{kg}$ ) and 8 female finswimmers ( age 24,5 $\pm 3,7 \mathrm{yrs}$., height 171,1 $\pm 10.4 \mathrm{~cm}$., weight 63,9 $\pm 5,1 \mathrm{~kg}$ ) performed a 15 meter monofin surface swim at full speed. Swimming was registered with a stationary GoPro Silver 3+ underwater video camera at 60 frames/second. Recordings were carried out during the 2015 Finswimming World Championship in Yantai, China and 2016 Finswimming World Championships Volos, Greece. Collected video material was analysed with Race analyser program (Estonia). Results: The average speed of male swimmers was $3.07 \pm 0.21 \mathrm{~m} / \mathrm{s}$ and the stroke rate $130.9 \pm 15.28 \mathrm{kick} / \mathrm{min}$. Pitching of the hands was $18 \pm 3.86 \mathrm{~cm}$, amplitude of the hip movement was $20.6 \pm 8.77 \mathrm{~cm}$ while the movement of the ankle was $43.6 \pm 9,72 \mathrm{~cm}$. Knee bending angle during a kick was $124.7 \pm 5,41 \mathrm{deg}$, hip angle at the same time was $169 \pm 5.94 \mathrm{deg}$ and angle of the hip at the end of a down beat was $148.6 \pm 7.95 \mathrm{deg}$. Female finswimmers had an average speed of $2,68 \pm 0.09 \mathrm{~m} / \mathrm{s}$ and a stroke rate of $118,4 \pm 11.3 \mathrm{kick} / \mathrm{min}$. Pitching of the hands was $15.3 \pm 6.3 \mathrm{~cm}$, amplitude of hip movements was $16.38 \pm 4.28 \mathrm{~cm}$, ankle movement was $42.38 \pm 8,16 \mathrm{~cm}$. Knee bending angle during a down beat was $121,5 \pm 8,12 \mathrm{deg}$ and a hip angle at the same time was $167.25 \pm 6.48$ deg. Angle of the hip at the end of a down beat was 148,86 \pm 8.82 deg. Conclusion: Current study found that elite men and women sprinter finswimmers can be typified according to characteristic swimming technique parameters in two classes: "fast" sprinters utilising speed of movements (S1) and "strong" sprinters with preference toward strength (S2). Further analysis is needed for confirmation. Key words: FINSWIMMING, TECHNIQUE, MODEL, HIP AND ANKLE ANGLES.
\end{abstract}

\section{Cite this article as:}

Kunitson, V., \& Port, K. (2017). Analysis of swimming technique among elite finswimmers. Journal of Human Sport and Exercise, 12(3proc), S831-S836. doi:https://doi.org/10.14198/jhse.2017.12.Proc3.07

\footnotetext{
Corresponding author. School of Natural Sciences and Helth, Tallinn University, Räägu 49, 11316 Tallinn, Estonia.

E-mail: vladimir.kunitson@gmail.com

11th World Congress of Performance Analysis of Sport, 16-18 November 2016. International Society of Performance Analysis of Sport. Alicante, Spain.

JOURNAL OF HUMAN SPORT \& EXERCISE ISSN 1988-5202

(c) Faculty of Education. University of Alicante

doi:10.14198/jhse.2017.12.Proc3.07
} 


\section{INTRODUCTION}

Finswimming is a water sport which is practised both underwater and on the surface (SF). During underwater the athlete swims using airbottle or apnoe. Surface swimming is practiced with snorkel in front of the head. Athletes use one big monofin for production of the propulsive movements. It has been demonstrated (Baly et al 2002) that propulsive movement starts at hip level and is based on whole body oscillation (Gautier et al 2004).

Oshita et al 2013 found that among women aerobic performance contributes to surface performance in shorter events from 200 until long distance of 1500 meters. Among men correlation with aerobic performance was established only with a long distance events from 800 to 1500 meters. Kunitson and Port 2015, 2013 found that performance in the sprint events in male finswimmers was relatively more strongly related to strength compared to female performance in short distances. They found that main muscle groups related to SF sprint swimming performance among men were knee extensors, hip and trunk flexors.

Finswimming kick cycle can be separated to a downward and an upward kicks. Rejman \& Ochmann 2005 found that finswimmers have the biggest speed during end of the down stroke and slowest when the up beat is going through transition to the down beat. Kick down starts with hip flexion, knee extension and feet dorsal flexion. For the athletes and coaches it is important to know how much is acceptable to bent from hips and knees.

Gautier et al 2004 studied differences between novice and experts fin swimmers combining men and women, and they found that experts $(119,25 \mathrm{deg})$ had smaller knee bending angle than novices (104,6 deg). While gender neutral grouping can serve the comparison purposes between novices and experts it can be argued that men and women swimmers have different optimal swimming techniques in finswimming and there are more parameters to be studied. Every sport should have a base model of a technique which one can use as a reference point. World best finswimmers can be used for the establishment of a basis models in finswimming relative to the gender and also to the distance. Aim of the current study was to describe sprint finswimming technique for women and men using the world best sprinters.

\section{METHODS}

10 male and 8 female athletes were filmed during world championship in finswimming in Yantai China. They were filmed with one stable Go Pro Hero 3+ Silver underwater video camera (USA) during a warm up and practises. Athletes were asked to swim 15 meters full speed both underwater and on the surface. Two swimming cycles were measured and average result was taken for analysis. All athletes participated voluntarily. All athletes were finalists and medal winners of World Championships.

With Race Analyzer (Estonia) computer program next parameters were measured:

- swimming speed,

- strokerate- stroke per minute

- amplitude of in $\mathrm{cm}$ : -fin, ankle, hip, wrist movement,

- degree of -knee bending, -hip angle during maximal knee bending and -hip angle to body and surface at the end of down beet, 
- also depth of wrist at the end of down beat in $\mathrm{cm}$ and

- time of down and up beat.

\section{RESULTS}

Men sprinters demonstrated average speed of $3.07 \pm 0.21 \mathrm{~m} / \mathrm{sec}$ and women $2.68 \pm 0.09 \mathrm{~m} / \mathrm{sec}$. Average stroke rate for men was $130.9 \pm 15.28$ strokes/min, while women had on average 118,4 $\pm 11,33$ strokes/min. Distance covered per one cycle among men was $1.43 \pm 0.17$ and women $1.39 \pm 0.17$ meters/stroke.

Table 1 one shows values of Stroke rate (ST), speed and distance per stroke (DPS). Correlation analysis showed a strong negative correlation between ST and DPS among women $(-0.95)$ and men $(-0.80)(p<0.05)$. Also correlation analysis showed that if stroke rate is higher then hip ankle and fin movement amplitude is smaller. If DPS is higher then hip and ankle movement amplitude is also bigger. Also the bigger the angle of knee is during bending (that means legs are straight) the smaller is ankle and fin movement amplitude.

Table 1. Max and min values of Speed, stroke rate and distance per stroke

Speed $\mathrm{m} / \mathrm{s} \quad$ Stroke rate per minute Distance per stroke (meters)

\begin{tabular}{lllllll}
\hline & Max & Min & Max & Min & Max & Min \\
Women & 2,77 & 2,5 & 129 & 102 & 1,65 & 1,15 \\
Men & 3,3 & 2,8 & 154 & 106 & 1,7 & 1,2 \\
\hline
\end{tabular}

Figure 1 shows in centimetres range of movement in wrist and hip during one swimming cycle and position of wrist in $\mathrm{cm}$ when finswimmer completes a down beat movement. Ankle movement amplitude was $42.38 \pm$ $8.16 \mathrm{~cm}$ among women and $43.6 \pm 9.72 \mathrm{~cm}$ among men. While fin movement amplitude was respectively 52 $\pm 8.6 \mathrm{~cm}$ and $52.6 \pm 8.49 \mathrm{~cm}$

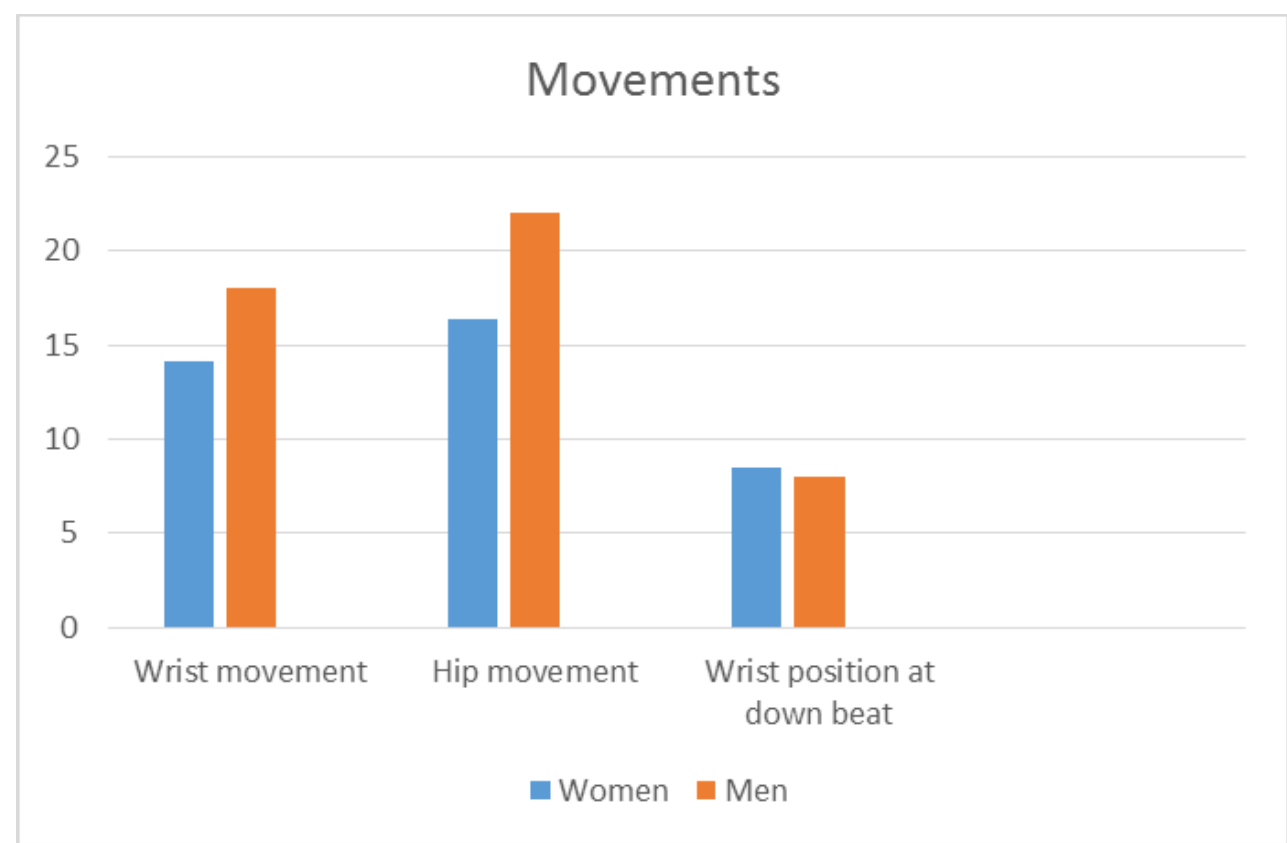

Figure 1. Range of movement in Wrist and hip movement among women and men elite finswimmers 


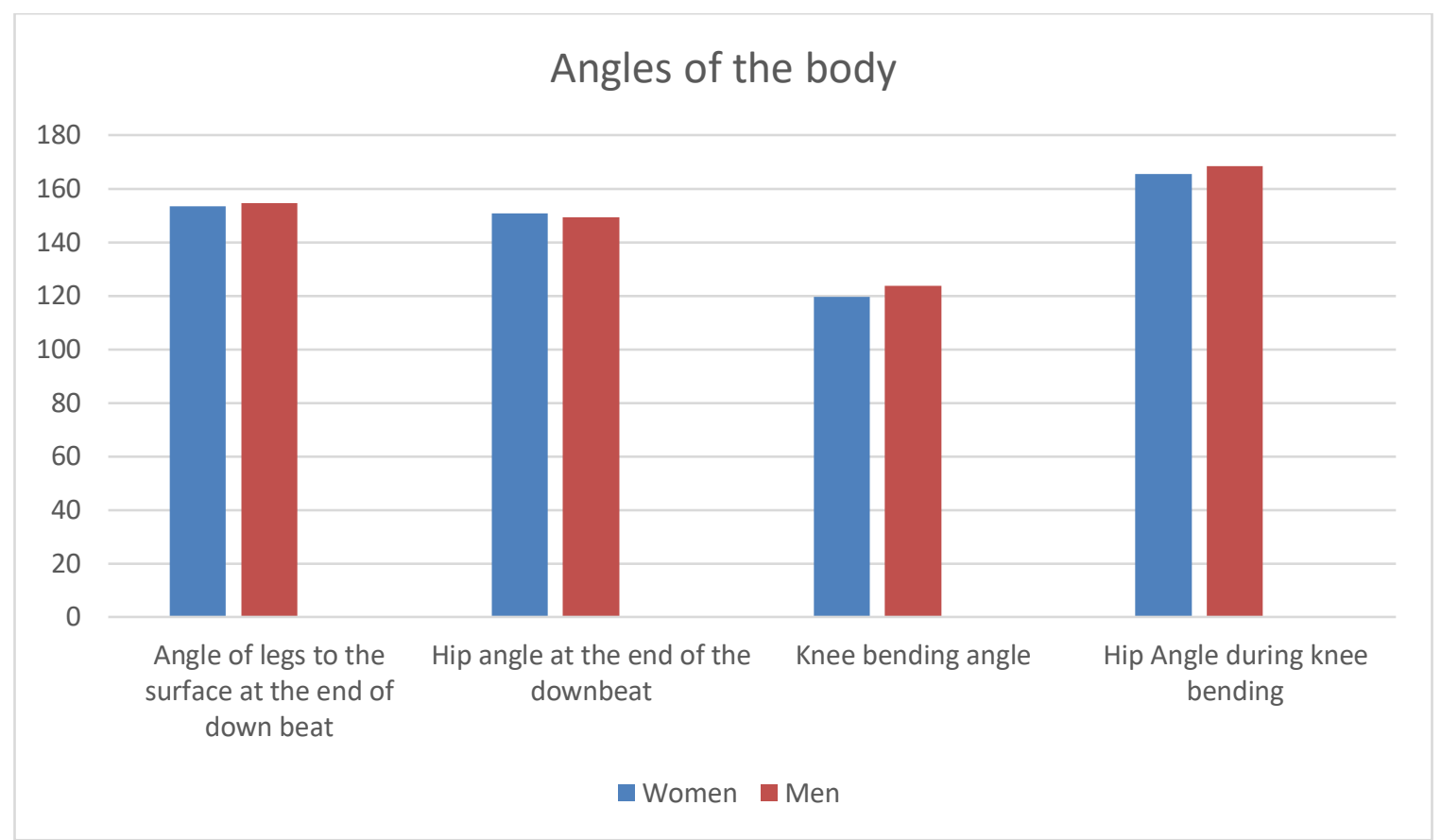

Figure 2. Angles of the body parts in degrees

Figure 2 and table 2 shows most important angles in the swimming technique of elite finswimmers of the current study.

Table 2. Mean \pm SD and min, max values of knee and hip angles.

\begin{tabular}{|c|c|c|c|c|c|c|c|c|c|}
\hline & \multicolumn{3}{|c|}{ Knee bending angle } & \multicolumn{3}{|c|}{$\begin{array}{l}\text { Hip bending angle during } \\
\text { knee bending }\end{array}$} & \multicolumn{3}{|c|}{$\begin{array}{l}\text { Hip angle at the end of the } \\
\text { down beat }\end{array}$} \\
\hline & Average & Min & $\operatorname{Max}$ & Average & Min & Max & Average & Min & Max \\
\hline Women & $121,5 \pm 8.12$ & 110 & 133 & $167.25 \pm 6.48$ & 158 & 176 & $148.88 \pm 8.82$ & 140 & 166 \\
\hline Men & $124.7 \pm 5.42$ & 113 & 132 & $169 \pm 5.94$ & 158 & 176 & $148.6 \pm 7.95$ & 132 & 157 \\
\hline
\end{tabular}

One objective in swimming is to minimize the resistance from the frontal surface. The frontal drag was biggest at the end or after the end of a down kick. Women had the lowest point of the fin at the $57,5 \pm 3.81 \mathrm{~cm}$ and men at $56.5 \pm 6.85 \mathrm{~cm}$ below the surface.

Among women correlation analysis revealed that with the bigger hip movement amplitude coincides with the bigger ankle (0.92) and fin (0.92) movement amplitudes and this is followed by lowered wrist position (0.84) during end of the down kick $(p<0.01)$. Likewise we found that the bigger hip movement coincides with more dropped legs at the end of the downward kick $(0.75) .(p<0.05)$

Further analysis looked at how much wrist (WHM) and monofin (MHM) move in horizontal plane in relation to $1 \mathrm{~cm}$ of hip movement and found a strong correlation between swimming speed and WHM (0.68). After omitting from analysis men finswimmers with low stroke rate (under $115 \mathrm{kick} / \mathrm{min})$ we found correlation between swimming speed and two parameters: amplitude of fin movement $(0.79)$ and DPS $(0.83) .(p<0.05)$. 


\section{DISCUSSION}

The goal of the study was to describe technique of elite level monofin swimmers with the aim to help coaches to teach proper technique to young finswimmers. Male finswimmers bend knee approximately to $125 \mathrm{deg}$, while hip is bent to $168 \mathrm{deg}$. At the end of downbeat finswimmers have maximal speed (Rejma ja Ochmann 2005,) while hip angle is $149 \mathrm{deg}$ and it is important to have hands and wrists in horizontal position to transfer speed from the down beat to horizontal velocity. For that finswimmers have to have flexible shoulder belt, so hands would be in effective horizontal position. Best finswimmers held their wrist in this position only $1-3 \mathrm{~cm}$ below the water surface. Although wrist amplitude during one cycle was from 6 (women) to $24 \mathrm{~cm}$ (men), but at the end of stroke swimmers managed to minimize it.

Women sprinters bend knees to 121 degrees while hip was on the average at the same time at 169 deg. During a down beat hip angle changed to $148 \mathrm{deg}$, which mean that the legs came closer to body during down kick or lower part of the spine was lifted. Similar values of knee bending, wrist amplitude and ankle amplitude were found by Gautier et al 2004. Oshita et al 2008 studied stroke rate and stroke length on $50 \mathrm{~m}$ SF men finswimmers at 12th world championship. He found that there was no difference between finalists and non-finalists in stroke rate. In the same study the stroke rate was 159 kicks per minute, while in current study we found that on the average swimmers demonstrated stroke rate od 130,9 stroke per minute. While in Oshita et al 2008 distance covered per stroke was $1.16 \mathrm{~m}$ we registered correspondingly 1.43 meters. This suggests on the possibility of different styles used in monofin swimming.

Correlation analysis between a stroke rate and a stroke length showed that if stroke rate is high then stroke length is low and reverse was also true. This hints to the idea that in finswimming there are two type of sprinters according to their stroke length and stroke rate.

First type of sprinters (S1) may be called "fast" sprinters. They have high stroke rate (men 140-150, women 120-130) and a low stroke length (men 1,2-1,3 m, women 1,15-1,3). So called "strong" sprinters (type S2) have a low stroke rate (men 110-130, women 100-110) and a high stroke length (men 1.4-1.6, women 1.351.65). Difference are related to the rigidity of a fin. As it is known a fin can be of a softer or harder material, S1 type swimmers swim with more softer fins while S2 type swimmers prefer to swim with more rigid monofins. Future studies are required to further the understanding of the technique parameters of both hypothetical types of sprinter finswimmers as well as possible gender related dependencies on these parameters.

\section{CONCLUSIONS}

Current study found that elite men and women sprinter finswimmers can be typified according to characteristic swimming technique parameters in one of two styles: "fast" sprinters utilising speed of movements (S1) and "strong" sprinters with preference toward strength (S2).

\section{REFERENCES}

1. Baly L, Favier D, Durey A, Berton E. Influence de la distance de course sur les parametres cinematiques de nage chez les nageurs avec palmes de haut niveau. Science \& Sports. 2002; 17(5): 263-265. https://doi.org/10.1016/S0765-1597(02)00171-5

2. Gautier, J., Baly, L., Zanone, P.-G., \& Watier, B. (2004). A Kinematic Study of Finswimming at Surface. Journal of Sports Science \& Medicine, 3(2), 91-95. 
3. Kunitson V, Rannama I, Port K. Relationship between isokinetic muscle strength and finswimming time. LASE. 2013; 4 (1): 55-61.

4. Kunitson V, Port K. (2015). Relationsip between isokinetic muscle strength and 100 meters finswimming time. Journal of Human Sport and Exercise, 10(Proc1), S482-S489. https://doi.org/10.14198/ihse.2015.10.Proc1.42

5. Oshita K, Ross M, Koisumi K, Yano S, Kashimoto S, Takahashi K, Kawakami M. Relationship of waving rate, waving length, and swimming velocity in the $50 \mathrm{~m}$ surface. Jap J Sci Swim W Eexerc. 2008; 11 (1): 14-18. https://doi.org/10.2479/swex.11.14

6. Oshito K, Ross M, Koizumi K, Tsuno T, Yano S. Gender difference of aerobic contribution to surface performance in finswimming: analysis using critical velocity method. Asian J Sport Med. 2013; 4: 256-262. https://doi.org/10.5812/asjsm.34244

7. Rejman $\mathrm{M}$, Ochmann $\mathrm{B}$. Application of artificial neural networks in monofin swimming technique assessment. Hum Mov. 20056 (1): 24-33. 